\title{
Application of Self-Curing Concrete Method Using Polyethylene Glycol
}

\author{
Edward Común, B.Sc ${ }^{1}$, Arleey Sanabria, B.Sc ${ }^{1}$, Luis Mosquera, $\mathrm{PhD}^{1}$ and Ana Torre, M.Sc ${ }^{1}$ \\ ${ }^{1}$ National University of Engineering,Peru, ecomuns@uni.pe, asanabriac@uni.pe,Imosquera@uni.edu.pe, anatorre@uni.edu.pe
}

\begin{abstract}
In this investigation the method of self-curing of concrete is applied using polyethylene glycol (PEG 400), with the aim of proposing an innovative alternative of curing concrete that suppresses the traditional external curing of the concrete indicated in ASTM C31, in order to obtain expected compression strength results, observing the development of concrete hydration processes. The experimental campaign included the production of 157 cylindrical specimens of dimensions $100 \times 200 \mathrm{~mm}$ and 18 beams of dimensions $150 \times 150 \times 500 \mathrm{~mm}$. Water-cement $(w / \mathrm{c})$ ratios $=0.70$, 0.60 and 0.45 and strength tests at 7,14 and 28 days were considered. Dosages of PEG 400 were used in $0.5 \%, 1 \%$ and $1.5 \%$ of the cement weight for the determination of the dosage that provides the best compressive strength results. Concrete properties were characterized such as splitting tensile strength, modulus of rupture, and its microscopic composition was observed using Scanning Electron Microscopy (SEM). Finally, it was obtained that at 28 days, the dosage of $1 \%$ of the cement weight for PEG 400, provides the most satisfactory results of compressive strength, splitting tensile strength and modulus of rupture for $w / c=0.70,0.60$ and 0.45 .

Keywords-- Self-curing Concrete, Polyethylene Glycol, Splitting Tensile Strength, Modulus of Rupture, Scanning Electron Microscopy.
\end{abstract}

\section{INTRODUCTION}

According to the critical scenario that manifests itself based on the deficiencies observed in the practice of concrete curing, which generates unsatisfactory characteristics of concrete, it is necessary to propose the use of products that can solve this problem from the design in order to create an alternative for suppressing the external curing process of concrete, considering the latter generates multiple uncertainties in the final strength of concrete, which varies according to the efficiency with which this procedure is developed.

ACI 308R-01 (2001) [1] and ASTM C 31 (2015) [2], propose the guide to curing concrete, describing curing methods and the materials used for these purposes. In addition, it exposes different types of curing according to the type of construction that is executed and the controls that are taken to guarantee the proper curing of concrete. Junaid (2015) [3] and Henkensiefken (2009) [4] provide a description and explanation about the internal curing of concrete and the importance of this technique to reduce the autogenous contraction and the formation of cracks in the concrete, Amaro (2002) [5] carried out a study of the performance of compressive strength of concrete according to traditional methods of external curing and describes its deficiencies. Baradan and Un (2011) [6] show the importance of temperature and humidity on the development of the mechanical properties of Portland cement under different curing regimes.

Digital Object Identifier (DOI):

http://dx.doi.org/10.18687/LACCEI2020.1.1.246

ISBN: 978-958-52071-4-1 ISSN: 2414-6390
Sundararaman (2016) [8] investigate materials that act as selfcuring agents in concrete and show the advantages of internal curing. Likewise, studies of self-curing concrete strength for different $\mathrm{w} / \mathrm{c}$ ratios were carried out with polyethylene glycol of molecular weight $400 \mathrm{~g} / \mathrm{mol}$, used as self-curing agent.

Mousa, Mahdy, Abdel-Reheem, Yehia (2015) [9] investigate the characteristics of self-curing concrete using presaturated lightweight aggregate, as well as the use of micro silica and polyethylene glycol of molecular weight $200 \mathrm{~g} / \mathrm{mol}$ to compare the results offered by these products with regard to water retention and durability.

This research seeks to propose the use of an admixture that promotes the self-curing of concrete, as is the case with polyethylene glycol (PEG 400), material that acts as a potential self-curing agent, which leads to great benefits such as cost reduction related to the curing process, greater water retention to improve the performance of cement hydration, saving water as a natural resource since this material will not be used to the curing process, possibility of providing an effective curing process in areas with limited access to water.

\section{A.1 Concrete curing}

The term "curing" is often used to describe the process by which concrete based on hydraulic cement matures and develops properties in a hardened state over time as a result of continuous hydration in the presence of sufficient water and adequate temperature. (ACI 308R, 2001) [1].

The curing of the concrete avoids self-drying, which is the internal drying of the concrete due to the water consumption resulting from the hydration of the cement. In relation to this, in mixtures of low a/c ratio, sealed against water loss or water entry, there is a greater risk that these mixtures can be dried internally. Thus, curing measures are required as soon as the concrete is at risk of drying and when such action damages the concrete or inhibits the development of the required properties (ACI 308R, 2001) [1].

\section{A.2 Self-curing or internal curing of concrete}

Self-curing concrete means that no labor is required to provide water in the concrete, or even no external curing is required after placement. The properties of this concrete are at least comparable and even better than those of concrete with traditional curing. Self-curing is an "internal curing" system in which a water-soluble polymer is added to the concrete mix.

This method overcomes the difficulty of ensuring that construction personnel employ effective curing procedures since the internal curing composition is a component of the concrete mix (Krishna \& Jaipal, 2017) [10]. Some materials that can provide internal water deposits are: lightweight aggregate, superabsorbent polymers (SAP) and shrinkage reducing admixture (SRA), such as polyethylene glycol. 
Currently, there are two main methods available for self-curing concrete. The first method uses lightweight aggregate (LWA) to supply an internal source of water, which can replace the water consumed by the chemical contraction during the hydration of the cement. The second method uses polyethylene glycol (PEG) that reduces the evaporation of water from the surface of the concrete and also helps in water retention (Abishek, 2016) [11].

Due to the difference in the chemical potential between the vapor and liquid phases, continuous evaporation of moisture takes place from the external surface of the concrete. The polymers added to the concrete mix mainly form hydrogen bonds with the water molecules and reduce the chemical potential of their molecules, which manifests itself in the reduction of vapor pressure, thus reducing the rate of evaporation of the surface (Daliya, 2016) [12].

\section{A.3Polyethylene Glycol (PEG)}

Polyethylene glycol, also known as polyethylene oxide (PEO), polyoxyethylene (POE) or macrogol, is a polyether produced by the condensation of ethylene oxide and water. The general formula of PEG is $\mathrm{H}(\mathrm{OCH} 2 \mathrm{CH} 2) \mathrm{n} \mathrm{OH}$, where $\mathrm{n}$ is the average number of repeating oxyethylene groups, typically from about 4 to about 180 . The low molecular weight compounds from $n=2$ to $\mathrm{n}=4$ are diethylene glycol, triethylene glycol and tetraethylene glycol respectively, which are produced as pure compounds. The abbreviation (PEG) is called in combination with a numerical suffix that indicates the average molecular weight (Krishna \& Jaipal, 2017) [10].

\section{EXPERIMENTAL DESCRIPTION}

Concrete mixes were designed for each of the following water-cement ratios: $\mathrm{w} / \mathrm{c}=0.70,0.60$ and 0.45 , which were selected for the most frequent use in the construction field for compliance with the usual strength requirements $(\mathrm{w} / \mathrm{c}=0.70$, $0.60)$, and durability requirements $(\mathrm{w} / \mathrm{c}=0.45)$.

Concrete specimens of $100 \times 200 \mathrm{~mm}$ were produced according to ASTM C192 (2016) [13] to be subsequently tested by compressive strength at the ages of 7, 14 and 28 days, following the procedure of ASTM C39 (2015) [14] for each w/c ratio studied.

Specimens were placed in a room with homogeneous and uniform temperature conditions of $23 \pm 2{ }^{\circ} \mathrm{C}$ and relative humidity of $70 \%$, in order to maintain homogeneous conditions in the samples until laboratory tests and to avoid uncertainties in the results, produced by humidity and temperature variations.

From the analysis of the results, the optimal dosage was determined by comparing the compressive strength results using a PEG 400 dosage of $0.5 \%, 1 \%$ and $1.5 \%$ of the cement weight, with the concrete standard.

With the defined optimum dosage of PEG 400, specimens were produced to determine other characteristics of the concrete at 28 days, such as splitting tensile strength, modulus of rupture, and Scanning Electron Microscopy (SEM) analysis.

\section{B.1 Materials}

In the present investigation, crushed stone from the UNI quarry was used as coarse aggregate, whose granulometric distribution resembles spindle 6 according to ASTM; coarse sand from the JICAMARCA quarry was used as fine aggregate, likewise, SOL Portland Type I cement, potable water and as an admixture, the polyethylene glycol with molecular weight 400 $\mathrm{g} / \mathrm{mol}$ (PEG 400) was used.

Main aggregate parameters were calculated in order to determine the characteristics of each aggregate, and the results are presented in Table 1.

TABLE I

\begin{tabular}{lll}
\multicolumn{3}{c}{ CHARACTERISTICS OF AGGREGATES } \\
\hline Characteristic & $\begin{array}{l}\text { Fine } \\
\text { aggregate }\end{array}$ & $\begin{array}{l}\text { Coarse } \\
\text { aggregate }\end{array}$ \\
\hline Specific gravity & 2.67 & 2.69 \\
Loose bulk density. $\left(\mathrm{kg} / \mathrm{m}^{3}\right)$ & 1632 & 1388 \\
Bulk density by rodding $\left(\mathrm{kg} / \mathrm{m}^{3}\right)$ & 1886 & 1569 \\
Absorption $(\%)$ & 0.60 & 1.00 \\
Moisture content $(\%)$ & 2.08 & 0.54 \\
Nominal maximum size & - & $3 / 4 "$ \\
Fineness modulus & 3.06 & 7.02 \\
\hline
\end{tabular}

\section{B.2 Concrete mix proportion}

The Walker methodology is used to obtain the best combination of aggregates for the relation $\mathrm{w} / \mathrm{c}=0.70$. Then, for all the water-cement ratios $(\mathrm{w} / \mathrm{c}=0.70,0.60$ and 0.45$)$, it was decided to maintain the distribution of aggregates in $50 \%$ of sand and $50 \%$ of stone with respect to the total volume of aggregates prepared for the concrete mix, in order to consider a homogeneous distribution of aggregates in the 3 cases of study and by workability conditions.

The identification of the samples produced in the investigation are detailed in Table 2.

TABLE 2

IDENTIFICATION OF SAMPLES

\begin{tabular}{ccc}
\hline Ident. & State of curing & $\%$ PEG 400 \\
\hline $\mathrm{SC}+0.0 \% \mathrm{wc}$ & Without curing & $+0.0 \%$ cement weight \\
$\mathrm{SC}+0.5 \% \mathrm{wc}$ & Without curing & $+0.5 \%$ cement weight \\
$\mathrm{SC}+1.0 \% \mathrm{wc}$ & Without curing & $+1.0 \%$ cement weight \\
$\mathrm{SC}+1.5 \% \mathrm{wc}$ & Without curing & $+1.5 \%$ cement weight \\
$\mathrm{C}+0.0 \% \mathrm{wc}$ & $\begin{array}{c}\text { Cured in water all } \\
\text { the time }\end{array}$ & $+0.0 \%$ cement weight \\
\hline
\end{tabular}

Likewise, Table 3, Table 4 and Table 5 show the proportion of materials per $\mathrm{m} 3$ corrected for moisture content and absorption of the aggregates for $\mathrm{w} / \mathrm{c}=0.70,0.60$ and 0.45 , respectively.

TABLE 3

CONCRETE MIX PROPORTION IN WET STATE BY MASS (KG) FOR W/C $=0.70$

\begin{tabular}{cccccc} 
Sample & Cement & Sand & Stone & Water & PEG400 \\
\hline SC $+0.0 \%$ wc & 311.4 & 904.9 & 895.5 & 209 & - \\
SC $+0.5 \%$ wc & 311.4 & 904.9 & 895.5 & 209 & 1.56
\end{tabular}

$18^{\text {th }}$ LACCEI International Multi-Conference for Engineering, Education, and Technology: "Engineering, Integration, and Alliances for a Sustainable Development" "Hemispheric Cooperation for Competitiveness and Prosperity on a Knowledge-Based Economy", 29-31 July 2020, Buenos Aires, Argentina. 2 


\begin{tabular}{cccccc}
$\mathrm{SC}+1.0 \% \mathrm{wc}$ & 311.4 & 904.9 & 895.5 & 209 & 3.11 \\
$\mathrm{SC}+1.5 \% \mathrm{wc}$ & 311.4 & 904.9 & 895.5 & 209 & 4.67 \\
$\mathrm{C}+0.0 \% \mathrm{wc}$ & 311.4 & 904.9 & 895.5 & 209 & - \\
\hline
\end{tabular}

TABLE 4

CONCRETE MIX PROPORTION IN WET STATE BY MASS (KG) FOR W/C $=0.60$

\begin{tabular}{cccccc} 
Sample & Cement & Sand & Stone & Water & PEG400 \\
\hline $\mathrm{SC}+0.0 \% \mathrm{wc}$ & 363.3 & 880.3 & 875.5 & 209 & - \\
$\mathrm{SC}+0.5 \% \mathrm{wc}$ & 363.3 & 880.3 & 875.5 & 209 & 1.82 \\
$\mathrm{SC}+1.0 \% \mathrm{wc}$ & 363.3 & 880.3 & 875.5 & 209 & 3.63 \\
$\mathrm{SC}+1.5 \% \mathrm{wc}$ & 363.3 & 880.3 & 875.5 & 209 & 5.45 \\
$\mathrm{C}+0.0 \% \mathrm{wc}$ & 363.3 & 880.3 & 875.5 & 209 & - \\
\hline
\end{tabular}

TABLE 5

CONCRETE MIX PROPORTION IN WET STATE BY MASS (KG) FOR W/C $=0.45$

\begin{tabular}{cccccc} 
Sample & Cement & Sand & Stone & Water & PEG400 \\
\hline SC $+0.0 \% w c$ & 484.4 & 828.6 & 822.7 & 210 & - \\
SC $+0.5 \% w c$ & 484.4 & 828.6 & 822.7 & 210 & 2.42 \\
SC $+1.0 \% w c$ & 484.4 & 828.6 & 822.7 & 210 & 4.84 \\
SC $+1.5 \% w c$ & 484.4 & 828.6 & 822.7 & 210 & 7.26 \\
C $+0.0 \% w c$ & 484.4 & 828.6 & 822.7 & 210 & - \\
\hline
\end{tabular}

\section{B.3 Preparation of the samples}

A total of 135 cylindrical concrete specimens of $100 \times 200 \mathrm{~mm}$ were produced according to ASTM C192 [13], which were tested in compressive strength at 7, 14 and 28 according to ASTM C39 [14] for each type of sample identified and for each $\mathrm{w} / \mathrm{c}$ ratio.

In addition, 22 additional cylindrical concrete specimens of $100 \times 200 \mathrm{~mm}$ were produced according to ASTM C192 [13], for the performance of splitting tensile strength tests and Scanning Electron Microscopy (SEM) tests for standard concrete samples and samples with PEG 400 with $1 \%$ of the weight of the cement for each $\mathrm{w} / \mathrm{c}$ ratio initially indicated.

Likewise, 18 prismatic beams of $150 \times 150 \times 500 \mathrm{~mm}$ were made for the execution of tests of modulus of rupture for samples of standard concrete and samples with PEG400 with $1 \%$ of cement weight for each $\mathrm{w} / \mathrm{c}$ ratio.

\section{RESULTS AND ANALYSIS}

\section{C.1 Results of compressive strength tests}

The concrete specimens were tested according to ASTM C39 [14] for $w / c=0.70,0.60$ and 0.45 . Fig. 1 shows tested samples.

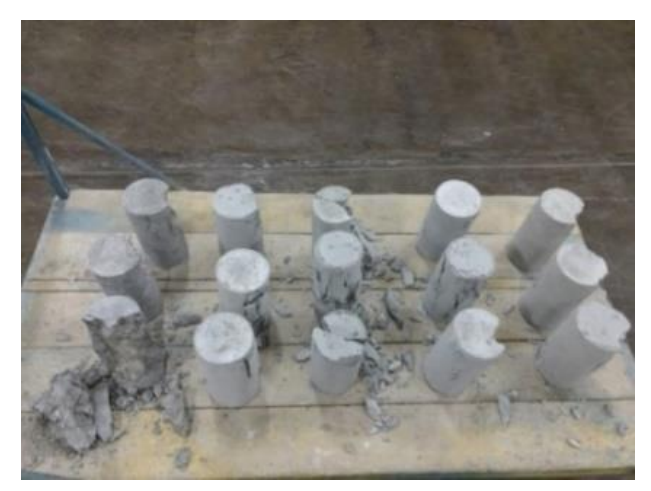

Fig. 1. Concrete specimens tested by compressive strength

Table 6, Table 7 and Table 8 summarize the averages of compressive strength obtained at 7,14 and 28 days for $\mathrm{w} / \mathrm{c}=0.70,0.60$ and 0.45 in each of the identified samples.

TABLE 6

AVERAGE COMPRESSIVE STRENGTH (KG/CM2) OBTAINED AT 7, 14 AND 28 DAYS FOR $\mathrm{W} / \mathrm{C}=0.70$

\begin{tabular}{cccc}
\hline Sample & 7 days & 14 days & 28 days \\
\hline SC $+0.0 \% w c$ & 174 & 187 & 208 \\
SC $+0.5 \%$ wc & 187 & 210 & 231 \\
SC $+1.0 \%$ wc & 211 & 220 & 247 \\
SC $+1.5 \%$ wc & 205 & 219 & 238 \\
$\mathrm{C}+0.0 \%$ wc & 206 & 216 & 256 \\
\hline
\end{tabular}

TABLE 7

AVERAGE COMPRESSIVE STRENGTH (KG/CM2) OBTAINED AT 7, 14 AND 28 DAYS FOR $\mathrm{W} / \mathrm{C}=0.60$

\begin{tabular}{cccc}
\hline Sample & 7 days & 14 days & 28 days \\
\hline $\mathrm{SC}+0.0 \% \mathrm{wc}$ & 227 & 252 & 276 \\
$\mathrm{SC}+0.5 \% \mathrm{wc}$ & 242 & 276 & 315 \\
$\mathrm{SC}+1.0 \% \mathrm{wc}$ & 269 & 299 & 335 \\
$\mathrm{SC}+1.5 \% \mathrm{wc}$ & 246 & 272 & 312 \\
$\mathrm{C}+0.0 \% \mathrm{wc}$ & 265 & 296 & 343 \\
\hline
\end{tabular}

TABLE 8

AVERAGE COMPRESSIVE STRENGTH (KG/CM2) OBTAINED AT 7, 14 AND 28 DAYS $\mathrm{FOR} W / \mathrm{C}=0.45$

\begin{tabular}{cccc}
\hline Sample & 7 days & 14 days & 28 days \\
\hline SC $+0.0 \% w c$ & 318 & 336 & 366 \\
SC $+0.5 \% w c$ & 353 & 410 & 441 \\
SC $+1.0 \% w c$ & 392 & 449 & 480 \\
SC $+1.5 \% w c$ & 350 & 406 & 434 \\
$\mathrm{C}+0.0 \% \mathrm{wc}$ & 348 & 386 & 455 \\
\hline
\end{tabular}

\section{C.2 Results of splitting tensile strength tests}

The concrete specimens were tested according to ASTM C496 [15] for a / $\mathrm{c}=0.70,0.60$ and 0.45. Fig. 2-3 show samples tested. 


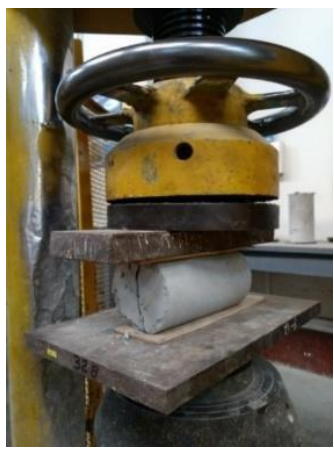

Fig. 2. Visualization of the failure in a concrete specimen by splitting tensile test

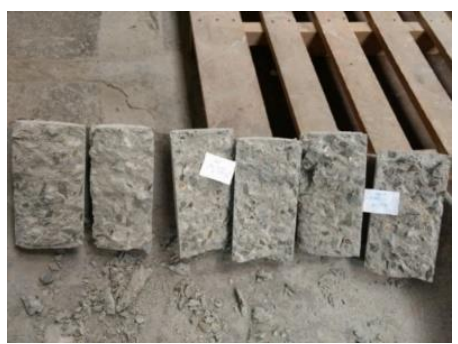

Fig. 3. Specimens of concrete tested by splitting tensile strength

Table 9 is shown below, which summarizes the average values of splitting tensile strength obtained at 28 days, for $\mathrm{w} / \mathrm{c}=0.70,0.60$ and 0.45 .

TABLE 9

AVERAGE SPLITTING TENSILE STRENGTH (KG/CM2) OBTAINED AT 28 DAYS FOR $\mathrm{W} / \mathrm{C}=0.70,0.60 \mathrm{Y} 0.45$

\begin{tabular}{cccc}
\hline $\mathrm{a} / \mathrm{c}$ & 0.70 & 0.60 & 0.45 \\
\hline $\mathrm{SC} 1.0 \%-28 \mathrm{D}$ & 23.1 & 28 & 37.4 \\
$\mathrm{C} 0.0 \%-28 \mathrm{D}$ & 23.9 & 26.8 & 35.6 \\
\hline
\end{tabular}

\section{C.3 Results of flexural strength tests on beams}

Concrete beams were tested for the determination of their modulus of rupture according to ASTM C78 [16] for $\mathrm{w} / \mathrm{c}=0.70$, 0.60 and 0.45 . Fig. $4-5$ show some of the beams tested.

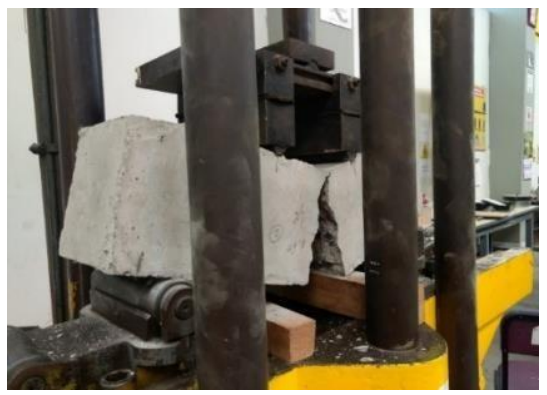

Fig. 4. Visualization of the failure in a concrete beam by flexural strength test

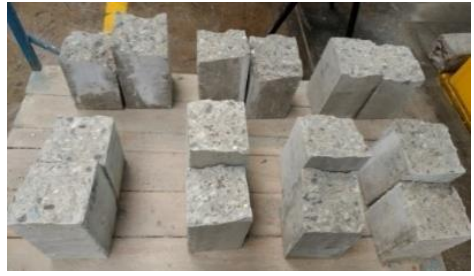

Fig. 5. Concrete specimens tested by flexural strength

Table 10 is shown below, which summarizes the average values of module of rupture obtained at 28 days, for $\mathrm{w} / \mathrm{c}=0.70$, 0.60 and 0.45 , tested in $150 \times 150 \times 500 \mathrm{~mm}$ beams.

TABLE 10

AVERAGE MODULUS OF RUPTURE (KG/CM2) OBTAINED AT 28 DAYS W/C $=0.70$, 0.60 Y 0.45

\begin{tabular}{cccc}
\hline $\mathrm{a} / \mathrm{c}$ & 0.70 & 0.60 & 0.45 \\
\hline $\mathrm{SC} 1.0 \%-28 \mathrm{D}$ & 32.0 & 37.8 & 47.1 \\
$\mathrm{C} 0.0 \%-28 \mathrm{D}$ & 34.3 & 39.6 & 46.1 \\
\hline
\end{tabular}

\section{C.4 Results of Scanning Electron Microscopy (SEM) tests}

The images corresponding to the microscopic characteristics of concrete specimens for $\mathrm{w} / \mathrm{c}=0.45$ are shown below. Fig. 6-7 show the German Scanning Electron Microscope ZEISS model EVO 10 and the placement of the concrete sample.

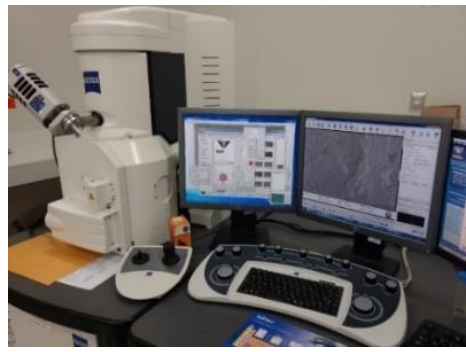

Fig. 6. Scanning Electron Microscope
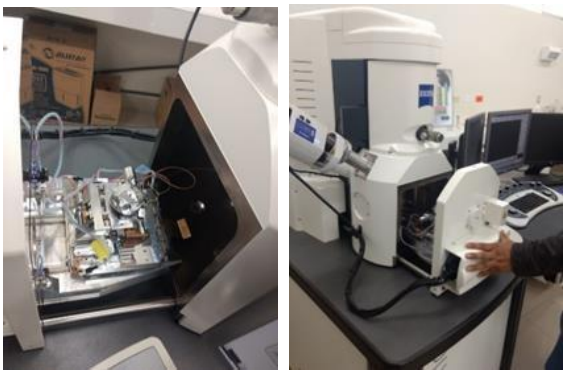

Fig. 7. Sample placement in the Scanning Electron Microscope 


\section{Results for $w / c=0.45$ at 7 days}

Fig. 8-9 show the microscopic characteristics of a $15 \times 15 \times 10 \mathrm{~mm}$ concrete sample coded as $\mathrm{SC}+1.0 \% \mathrm{wc}$ for $\mathrm{w} / \mathrm{c}=0.45$ at 7 days, observed in the scanning electron microscope with a $10000 \mathrm{x}$ and $50000 \mathrm{x}$ amplification, respectively.

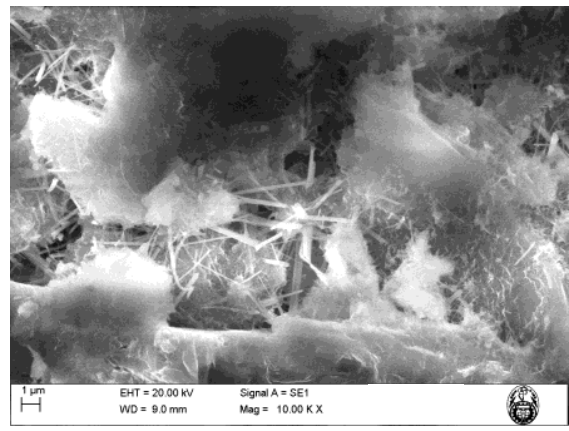

Fig. 8. Observation in the scanning electron microscope of sample $\mathrm{SC}+$ $1.0 \% \mathrm{wc}$ at 7 days for $\mathrm{w} / \mathrm{c}=0.45$, with an amplification of $10000 \mathrm{x}$

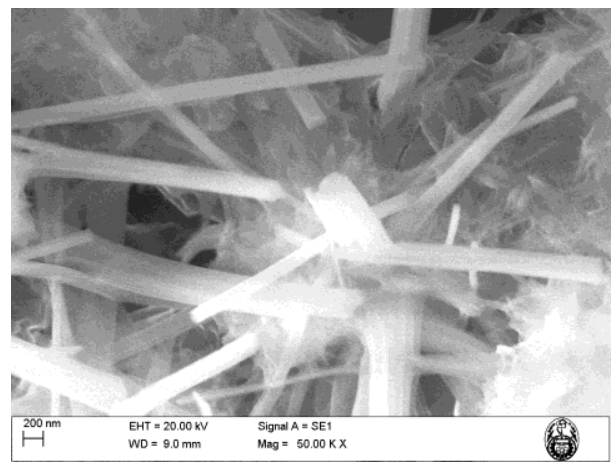

Fig. 9. Observation in the scanning electron microscope of sample SC + $1.0 \% \mathrm{wc}$ at 7 days for $\mathrm{w} / \mathrm{c}=0.45$, with an amplification of $50000 \mathrm{x}$

Fig. 10-11 show the microscopic characteristics of a $15 \times 15 \times 10 \mathrm{~mm}$ concrete sample coded as $\mathrm{C}+0.0 \%$ wc for $\mathrm{w} / \mathrm{c}=0.45$ at 7 days, observed in the scanning electron microscope with a $10000 \mathrm{x}$ and $50000 \mathrm{x}$ amplification, respectively.

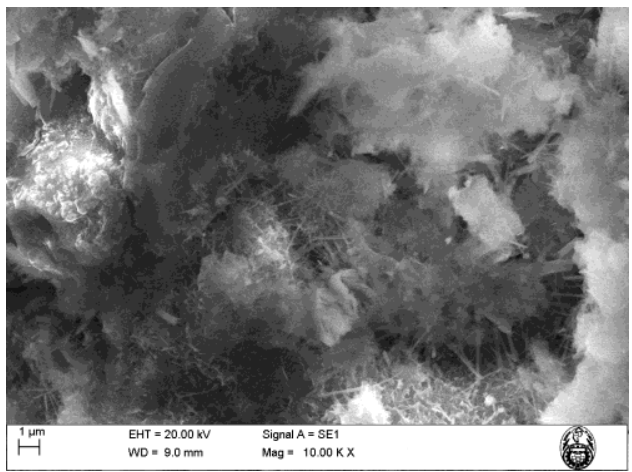

Fig. 10. Observation in the scanning electron microscope of sample $\mathrm{C}+$ $0.0 \% \mathrm{wc}$ at 7 days for $\mathrm{w} / \mathrm{c}=0.45$, with an amplification of $10,000 \mathrm{x}$

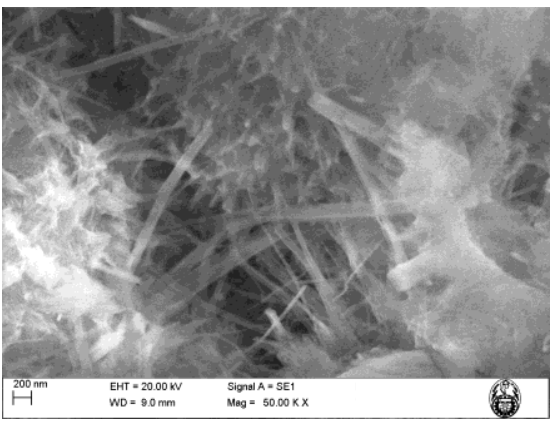

Fig. 11. Observation in the scanning electron microscope of sample $\mathrm{C}+$ $0.0 \% \mathrm{wc}$ at 7 days for $\mathrm{w} / \mathrm{c}=0.45$, with an amplification of $50000 \mathrm{x}$

\section{Results for $w / c=0.45$ at 28 days}

Fig. 12-13 show the microscopic characteristics of a $15 \times 15 \times 10 \mathrm{~mm}$ concrete sample coded as $\mathrm{SC}+1.0 \% \mathrm{wc}$ for $\mathrm{w} / \mathrm{c}=0.45$ at 28 days, observed in the scanning electron microscope with a $10000 \mathrm{x}$ and $50000 \mathrm{x}$ amplification, respectively.

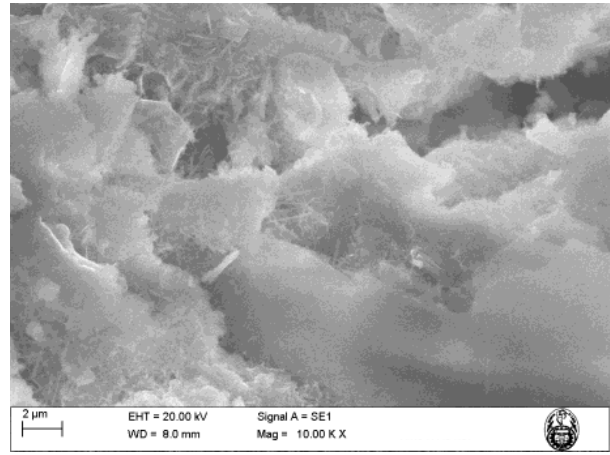

Fig. 12. Observation in the scanning electron microscope of sample SC + $1.0 \% \mathrm{wc}$ at 28 days for $\mathrm{w} / \mathrm{c}=0.45$, with an amplification of $10000 \mathrm{x}$

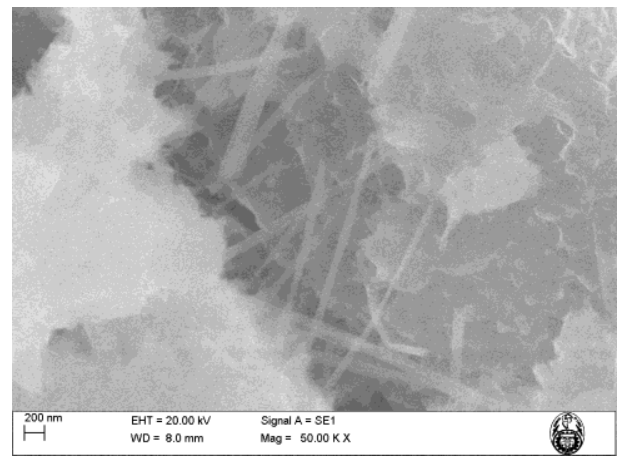

Fig. 13. Observation in the scanning electron microscope of sample SC + $1.0 \% \mathrm{wc}$ at 28 days for $\mathrm{w} / \mathrm{c}=0.45$, with an amplification of $50000 \mathrm{x}$

Fig. 14-15 show the microscopic characteristics of a $15 \times 15 \times 10 \mathrm{~mm}$ concrete sample coded as $\mathrm{C}+0.0 \%$ wc for $\mathrm{w} / \mathrm{c}=0.45$ at 28 days, observed in the scanning electron microscope with a $10000 \mathrm{x}$ and 50 000x amplification, respectively. 


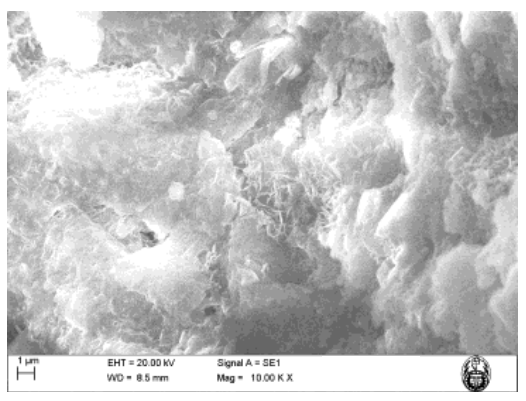

Fig. 14. Observation in the scanning electron microscope of sample $\mathrm{C}+$ $0.0 \% \mathrm{wc}$ at 28 days for $\mathrm{w} / \mathrm{c}=0.45$, with an amplification of $10,000 \mathrm{x}$

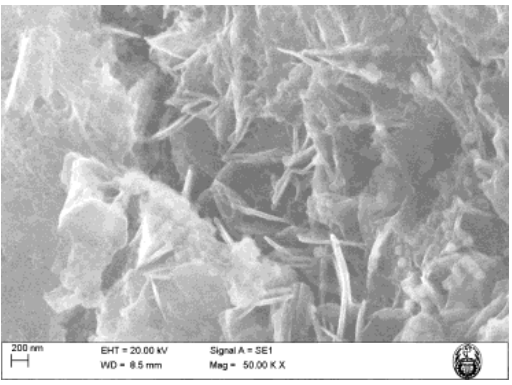

Fig. 15. Observation in the scanning electron microscope of sample $\mathrm{C}+$ $0.0 \% \mathrm{wc}$ at 28 days for $\mathrm{w} / \mathrm{c}=0.45$, with an amplification of $50000 \mathrm{x}$

\section{C.5. Analysis of results}

Many equations have been published to characterize the relationship between compressive strength and curing time, among these, the exponential and hyperbolic equations have been recommended in ASTM C 1074 [17]. The exponential dependence of compressive strength with curing time $(\mathrm{S}(\mathrm{t}))$ is expressed by the equation:

$$
S(t)=S_{u} \cdot \exp \left[-\left(\frac{\tau}{t}\right)^{\beta}\right]
$$

and allows to estimate the maximum compressive strength value of a type of concrete.

Where,

$\mathrm{Su}$ : is the maximum compressive strength to reach

$\mathrm{t}$ : time in hours

$\tau$ : time constant

$\beta$ : constant form

Analysis of compressive strength results for $w / c=0.70$

From Table 6, Fig. 16-19 and Table 11 are constructed, where it is observed that for $\mathrm{w} / \mathrm{c}=0.70$, the best compression characteristics are found for specimens containing $1 \%$ of PEG400 with average compressive strength $2.4 \%$ higher than the average compressive strength of the standard concrete at 7 days (See Fig. 16). At 14 days, 1.9\% higher than the average compressive strength of the standard concrete (See Fig. 17). At 28 days, $3.5 \%$ lower than the average compressive strength of the standard concrete (See Fig. 18).

Fig. 19 shows the compressive strength achieved by this concrete over the curing time. The results of the strength data adjustment achieved versus curing time with equation [1] are shown in Table 11 and the adjustment curve for sample $\mathrm{SC}+$ $1.0 \%$ is shown in Fig. 20.

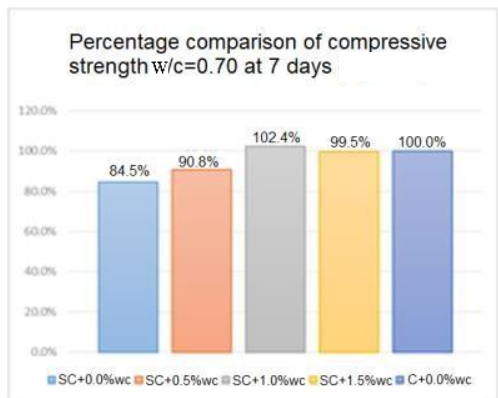

Fig. 16. Percentage comparison of compressive strength obtained at 7 days for $\mathrm{w} / \mathrm{c}=0.70$

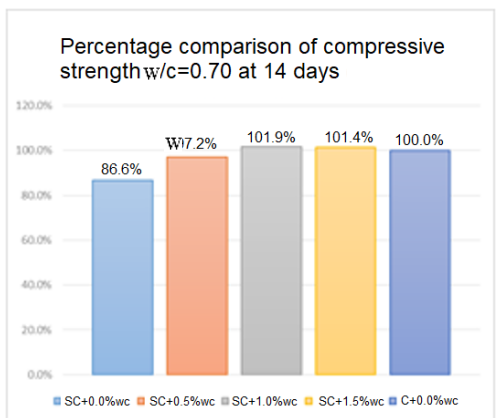

Fig. 17. Percentage comparison of compressive strength obtained at 14 days for $\mathrm{w} / \mathrm{c}=0.70$

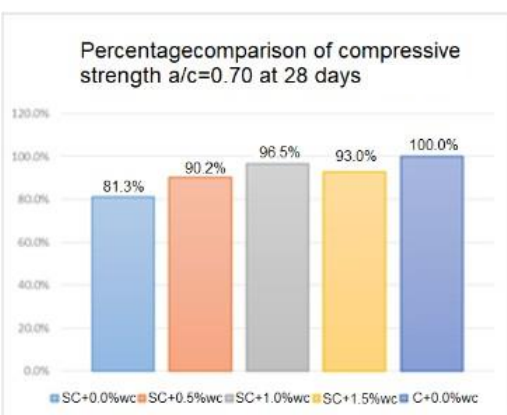

Fig. 18. Percentage comparison of compressive strength obtained at 28 days for $\mathrm{w} / \mathrm{c}=0.70$

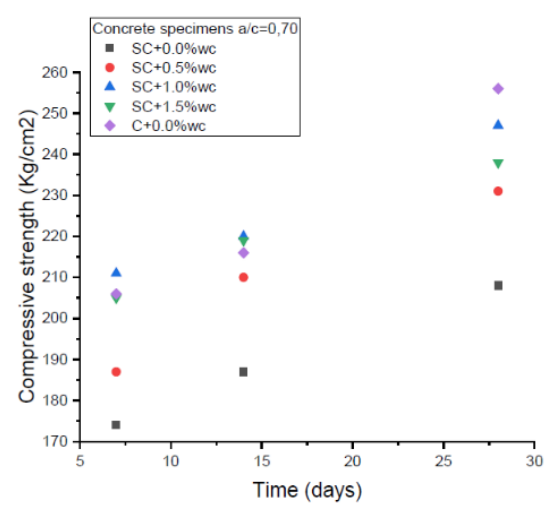

Fig. 19. Compressive strength values obtained at 7, 14 and 28 days for $\mathrm{w} / \mathrm{c}=0.70$ 


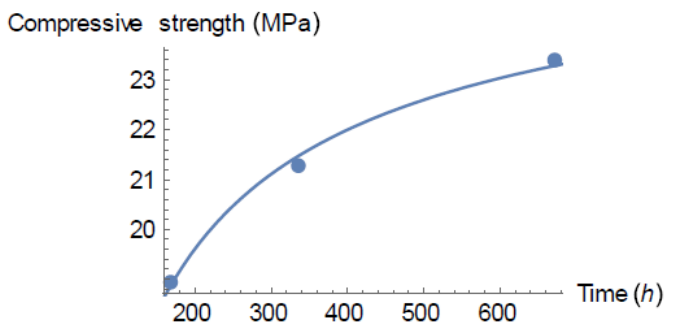

Fig. 20. Compressive strength obtained at 28 days for $\mathrm{SC}+1.0 \% \mathrm{wc}$; $\mathrm{w} / \mathrm{c}=$ 0.70 and adjustment curve with exponential function.

TABLE 11

RESULTS OF THE NON-LINEAR ADJUSTMENT OF THE COMPRESSIVE STRENGTH AVERAGES (KG/CM2) OBTAINED AT 7, 14 AND 28 DAYS FOR W/C $=0.70$, USING THE COMPRESSIVE STRENGTH-CURING TIME EXPONENTIAL FUNCTION

\begin{tabular}{rccc}
\hline & $\begin{array}{c}\mathrm{Su} \\
(\mathrm{MPa})\end{array}$ & $\begin{array}{c}\tau \\
(\mathrm{h})\end{array}$ & $\beta$ \\
\hline $\mathrm{SC}+0.0 \% \mathrm{wc}$ & 23.37 & 30.99 & 0.71 \\
$\mathrm{SC}+0.5 \% \mathrm{wc}$ & 26.62 & 34.98 & 0.68 \\
$\mathrm{SC}+1.0 \% \mathrm{wc}$ & 26.79 & 30.0 & 0.80 \\
$\mathrm{SC}+1.5 \% \mathrm{wc}$ & 26.06 & 24.99 & 0.75 \\
$\mathrm{C}+0.0 \% \mathrm{wc}$ & 29.89 & 41.01 & 0.65 \\
\hline
\end{tabular}

Analysis of compressive strength results for $w / c=0.60$

From Table 7, Fig. 21-24 are constructed, where it is observed that for $\mathrm{w} / \mathrm{c}=0.60$, the best compression characteristic corresponds to specimens containing $1 \%$ of PEG400 with average compressive strength $1.5 \%$ higher than the average compressive strength of the standard concrete at the age of 7 days (See Fig. 21). At 14 days, $1 \%$ higher (See Fig. 22), and at 28 days, $2.3 \%$ lower (See Fig. 23).

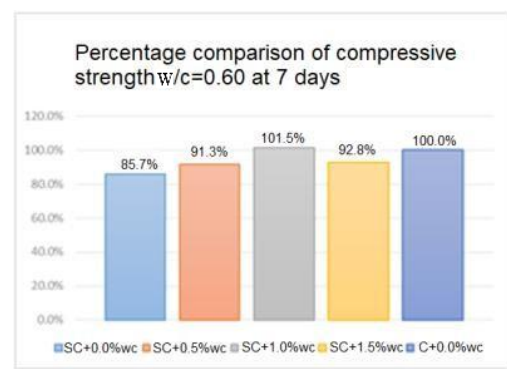

Fig. 21. Percentage comparison of compressive strength obtained at 7 days for $\mathrm{w} / \mathrm{c}=0.60$

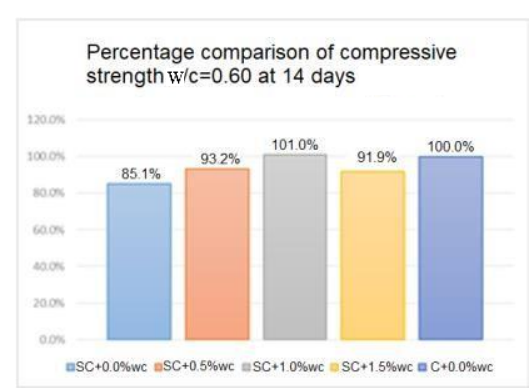

Fig. 22. Percentage comparison of compressive strength obtained at 14 days for $\mathrm{w} / \mathrm{c}=0.60$
The increase in compressive strength versus curing time for this concrete is shown in Fig. 24. From the adjustment of these experimental data with equation [1], the data recorded in Table 12 are obtained and the adjustment curve for sample $\mathrm{SC}+1.0 \%$ is shown in Fig. 25.

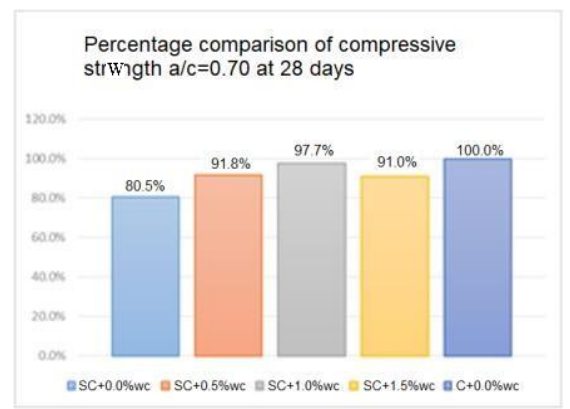

Fig. 23. Percentage comparison of compressive strength obtained at 28 days for $\mathrm{w} / \mathrm{c}=0.60$

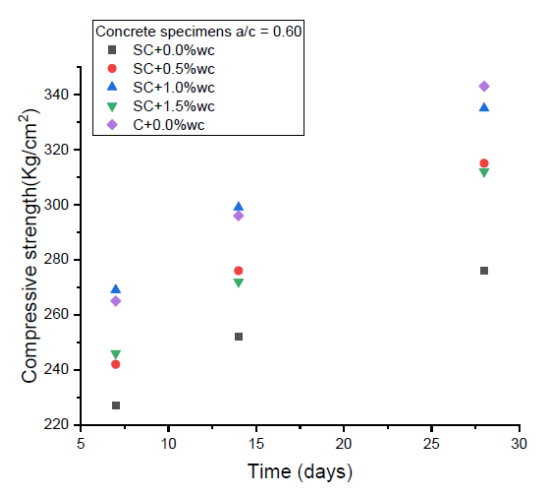

Fig. 24. Compressive strength values obtained at 7, 14 and 28 days for $\mathrm{w} / \mathrm{c}=0.60$

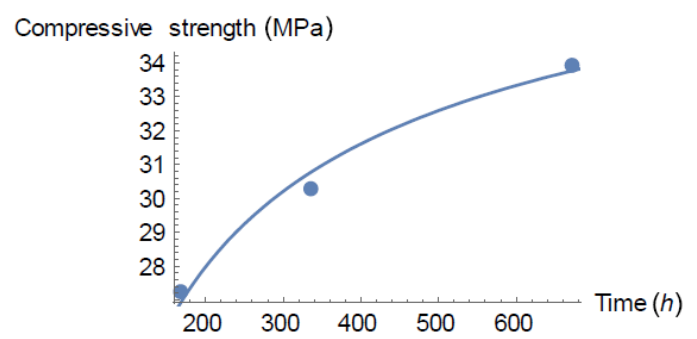

Fig. 25. Compressive strength obtained at 28 days for $\mathrm{SC}+1.0 \% \mathrm{wc}$; $\mathrm{w} / \mathrm{c}=0.60$ and adjustment curve with exponential function.

TABLE 12

RESULTS OF THE NON-LINEAR ADJUSTMENT OF THE COMPRESSIVE STRENGTH AVERAGES (KG/CM2) OBTAINED AT 7, 14 AND 28 DAYS FOR W/C $=0.60$, USING THE COMPRESSIVE STRENGTH-CURING TIME EXPONENTIAL FUNCTION

\begin{tabular}{rccc}
\hline & $\begin{array}{c}\mathrm{Su} \\
(\mathrm{MPa})\end{array}$ & $\begin{array}{c}\tau \\
(\mathrm{h})\end{array}$ & $\beta$ \\
\hline $\mathrm{SC}+0.0 \% \mathrm{wc}$ & 31.89 & 30.99 & 0.65 \\
$\mathrm{SC}+0.5 \% \mathrm{wc}$ & 38.87 & 51.01 & 0.62 \\
$\mathrm{SC}+1.0 \% \mathrm{wc}$ & 41.61 & 34.98 & 0.53 \\
$\mathrm{SC}+1.5 \% \mathrm{wc}$ & 36.62 & 45.97 & 0.69 \\
$\mathrm{C}+0.0 \% \mathrm{wc}$ & 38.39 & 61.01 & 0.92 \\
\hline
\end{tabular}


Analysis of compressive strength results for $w / c=0.45$

From Table 8, Fig. 26-29 are constructed where it is observed that for $\mathrm{w} / \mathrm{c}=0.45$, the best compression characteristics are found for specimens containing $1 \%$ of PEG400 with average compression resistance $12.6 \%$ higher than the average compressive strength of the standard concrete at 7 days (See Fig. 26). At 14 days, 16.3\% higher than the average compressive strength of the standard concrete (See Fig. 27). At 28 days, $5.5 \%$ higher than the average compressive strength of the standard concrete (See Fig. 28).

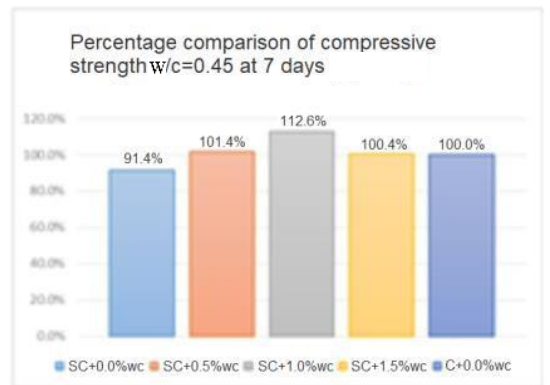

Fig. 26. Percentage comparison of compressive strength obtained at 7 days for $\mathrm{w} / \mathrm{c}=0.45$

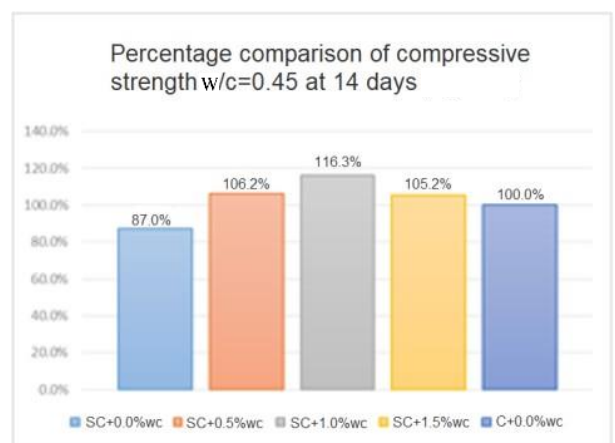

Fig. 27. Percentage comparison of compressive strength obtained at 14 days for $\mathrm{w} / \mathrm{c}=0.45$

The increase in compressive strength versus curing time for this concrete is shown in Fig. 29. From the adjustment of these experimental data with equation [1], the data recorded in Table 13 are obtained and the adjustment curve for sample $\mathrm{SC}+1.0 \%$ is shown in Fig. 30.

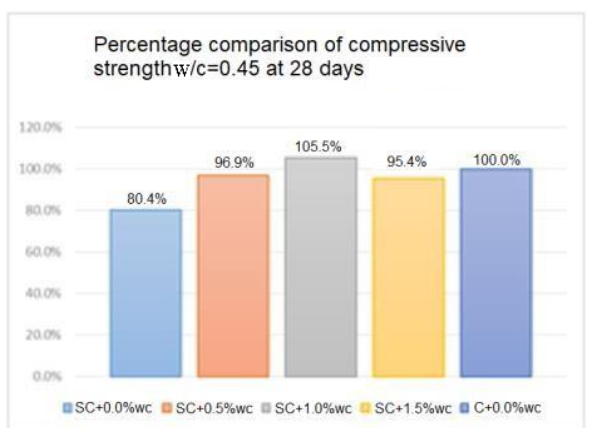

Fig. 28. Percentage comparison of compressive strength obtained at 28 days for $\mathrm{w} / \mathrm{c}=0.45$

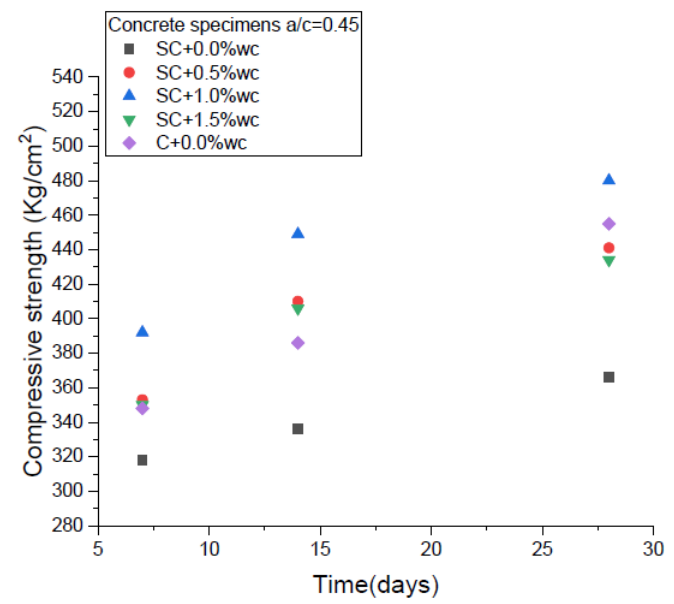

Figure 29. Compressive strength values obtained at 7, 14 and 28 days for $\mathrm{w} / \mathrm{c}=0.45$

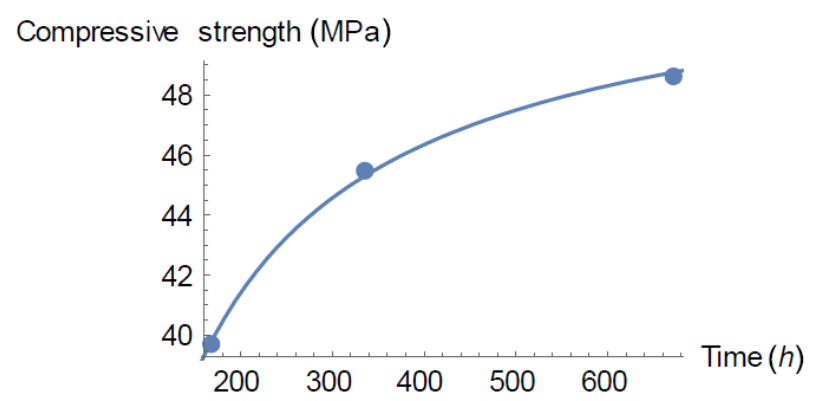

Figure 30. Compressive strength obtained at 28 days for $\mathrm{SC}+1.0 \% \mathrm{wc} ; \mathrm{w} / \mathrm{c}=0.45$ and adjustment curve with exponential function.

TABLA 13

RESULTS OF THE NON-LINEAR ADJUSTMENT OF THE COMPRESSIVE STRENGTH AVERAGES (KG/CM2) OBTAINED AT 7,14 AND 28 DAYS FOR $\mathrm{W} / \mathrm{C}=0.45$, USING THE COMPRESSIVE STRENGTH-CURING TIME EXPONENTIAL FUNCTION

\begin{tabular}{rccc}
\hline & $\begin{array}{c}\mathrm{Su} \\
(\mathrm{MPa})\end{array}$ & $\begin{array}{c}\tau \\
(\mathrm{h})\end{array}$ & $\beta$ \\
\hline & & & \\
$\mathrm{SC}+0.0 \% \mathrm{wc}$ & 40.47 & 20.99 & 0.68 \\
$\mathrm{SC}+0.5 \% \mathrm{wc}$ & 48.25 & 47.99 & 0.97 \\
$\mathrm{SC}+1.0 \% \mathrm{wc}$ & 53.57 & 38.99 & 0.83 \\
$\mathrm{SC}+1.5 \% \mathrm{wc}$ & 47.53 & 46.99 & 0.97 \\
$\mathrm{C}+0.0 \% \mathrm{wc}$ & 53.97 & 51.98 & 0.68 \\
\hline
\end{tabular}

Analysis of splitting tensile strength results for $w / c=0.70$

From Table 9, Fig. 31 is constructed, where it is observed that, for $\mathrm{w} / \mathrm{c}=0.70$, at 28 days, the best splitting tensile strength characteristics are found for specimens containing $1 \%$ of PEG400 with an average splitting tensile strength of $23.9 \mathrm{~kg} / \mathrm{cm}^{2}, 3.3 \%$ lower than the average splitting tensile strength of the standard concrete, which has $23.1 \mathrm{~kg} / \mathrm{cm}^{2}$. 


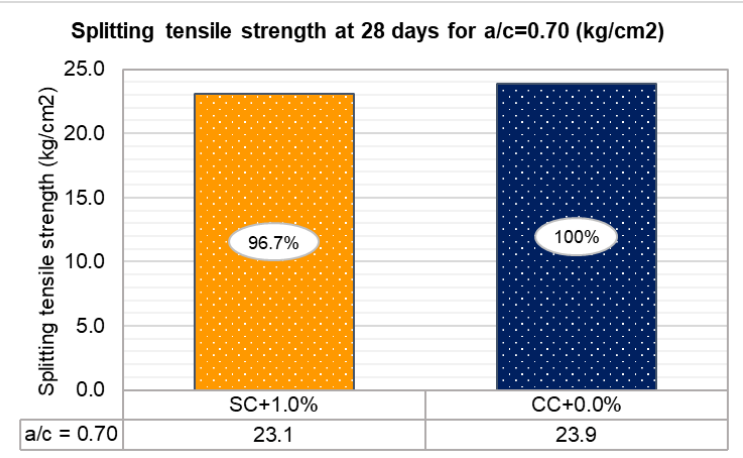

Figure 31. Results of splitting tensile strength at 28 days for $\mathrm{w} / \mathrm{c}=0.70$

Analysis of splitting tensile strength results for $w / c=0.60$

From Table 9, Fig. 32 is constructed, where it is observed that, for $\mathrm{w} / \mathrm{c}=0.60$, at 28 days, the best splitting tensile strength characteristics are found for specimens containing $1 \%$ of PEG400 with an average splitting tensile strength of $28 \mathrm{~kg} / \mathrm{cm}^{2}$, $4.5 \%$ higher than the average splitting tensile strength of the standard concrete, which has $26.8 \mathrm{~kg} / \mathrm{cm}^{2}$.

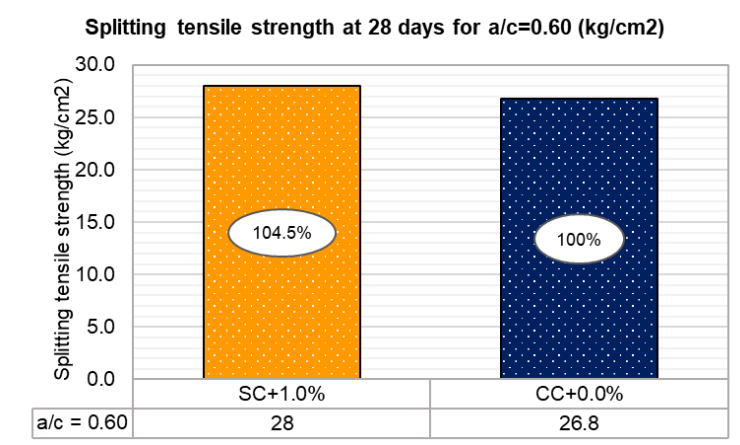

Figure 32. Results of splitting tensile strength at 28 days for $\mathrm{w} / \mathrm{c}=0.60$

Analysis of splitting tensile strength results for $w / c=0.45$

From Table 9, Fig. 33 is constructed, where it is observed that, for $\mathrm{w} / \mathrm{c}=0.45$ at 28 days, best splitting tensile strength characteristics are found for specimens containing $1 \%$ of PEG400 with an average splitting tensile strength of $37.4 \mathrm{~kg} / \mathrm{cm}^{2}, 5.1 \%$ lower than the average splitting tensile strength of the standard concrete, which has $35.6 \mathrm{~kg} / \mathrm{cm}^{2}$.

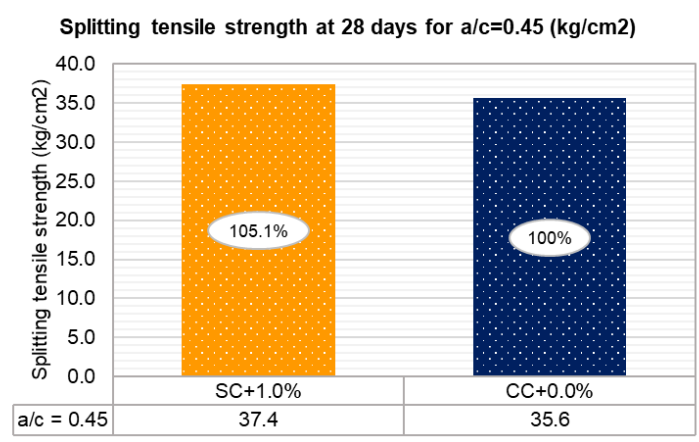

Figure 33. Results of splitting tensile strength at 28 days for $\mathrm{w} / \mathrm{c}=0.45$

Analysis of modulus of rupture results for $w / c=0.70$

From Table 10, Fig. 34 is constructed, where it is observed that, for $\mathrm{w} / \mathrm{c}=0.70$ at 28 days, the best modulus of rupture characteristics are found for specimens containing $1 \%$ of PEG400 with an average modulus of rupture of $32 \mathrm{~kg} / \mathrm{cm}^{2}, 6.7 \%$ lower than the average modulus of rupture of the standard concrete, which has $34.3 \mathrm{~kg} / \mathrm{cm}^{2}$.

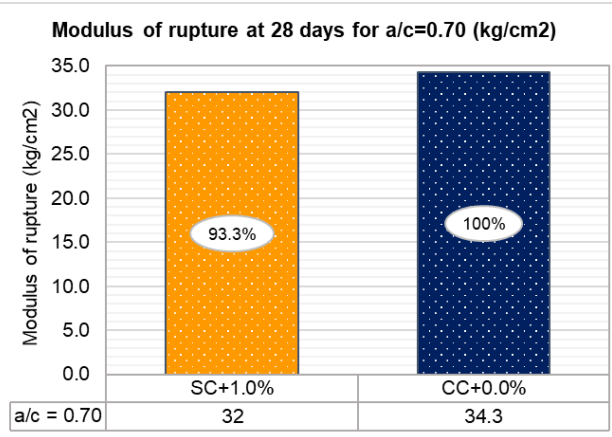

Figure 34. Results of modulus of rupture at 28 days for $w / c=0.70$

Analysis of modulus of rupture results for $w / c=0.60$

From Table 10, Fig. 35 is constructed, where it is observed that, for $\mathrm{w} / \mathrm{c}=0.60$ at 28 days, the best modulus of rupture characteristics are found for specimens containing $1 \%$ of PEG400 with an average modulus of rupture of $37.8 \mathrm{~kg} / \mathrm{cm}^{2}$, $4.5 \%$ lower than the average modulus of rupture of the standard concrete, which has $39.6 \mathrm{~kg} / \mathrm{cm}^{2}$.

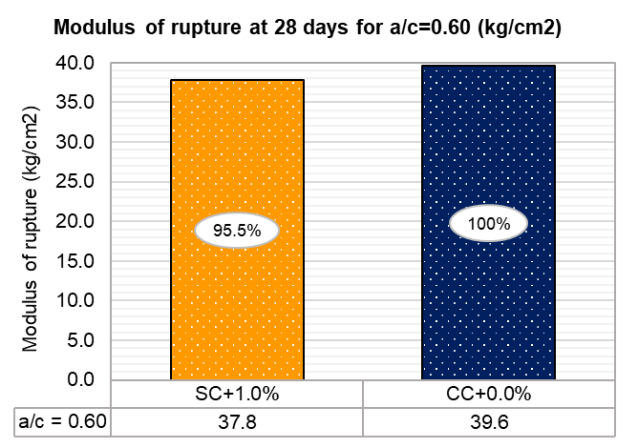

Figure 35. Results of modulus of rupture at 28 days for $w / c=0.60$

Analysis of modulus of rupture results for $w / c=0.45$

From Table 10, Fig. 36 is constructed, where it is observed that, for $\mathrm{w} / \mathrm{c}=0.45$ at 28 days, the best modulus of rupture characteristics are found for specimens containing $1 \%$ of PEG400 with an average modulus of rupture of $47.1 \mathrm{~kg} / \mathrm{cm}^{2}$, $2.2 \%$ higher than the average modulus of rupture of the standard concrete, which has $46.1 \mathrm{~kg} / \mathrm{cm}^{2}$.

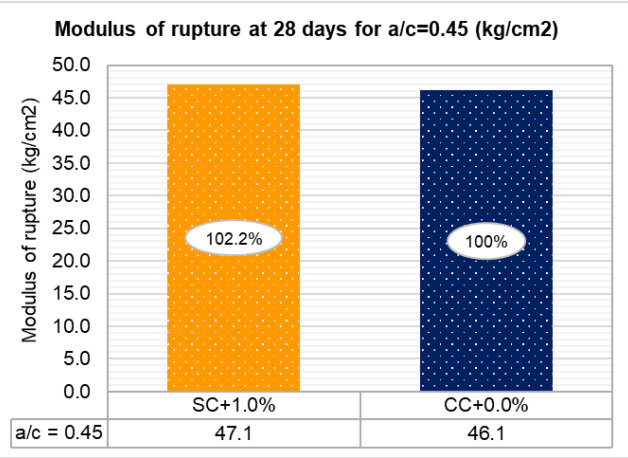

Figure 36. Results of modulus of rupture at 28 days for $\mathrm{w} / \mathrm{c}=0.45$

$18^{\text {th }}$ LACCEI International Multi-Conference for Engineering, Education, and Technology: "Engineering, Integration, and Alliances for a Sustainable Development" "Hemispheric Cooperation for Competitiveness and Prosperity on a Knowledge-Based Economy", 29-31 July 2020, Buenos Aires, Argentina. 9 
Analysis of results of SEM tests for $w / c=0.45$ at 7 days

The analysis encompasses the qualitative comparison of the images recorded with the Scanning Electron Microscopy (SEM) tests, based on Fig. 8-11. Thus, it is observed that, at 7 days, the characteristics of the formation of the crystals, (concrete hydration products) are similar both for samples containing $1 \%$ of PEG400 without curing and for samples that not contain PEG400 and that were cured in water all the time.

Likewise, in both cases the multidirectional bonds between cement particles that begin to become denser in the first days are observed more clearly, which confers the increase in strength as these hydration products become denser over time.

\section{Analysis of results of SEM tests for $w / c=0.45$ at 28 days}

The analysis covers the qualitative comparison of the images recorded with the Scanning Electron Microscopy (SEM) tests, from Fig. 12-15. At 28 days, the characteristics of the formation of the crystals, (concrete hydration products) are similar both for samples containing 1\% of PEG400 without curing and for samples that not contain peg 400 and that were cured in water all the time.

Likewise, in both cases the multidirectional bonds between cement particles are observed in less quantity and clarity compared to 7 days, since for this age almost all of the reactions that confer resistance to concrete have already occurred; consequently, the formation of new hydration products has a very low rate and finally consolidated crystals are observed.

\section{CONCLUSIONS}

On the basis of experimental tests, results and analysis, the following conclusions are drawn:

1. The application of PEG 400 as a self-curing method provided comparable and superior results of compressive strength, splitting tensile strength and flexural strength in comparison with the conventionally cured concrete for $\mathrm{w} / \mathrm{c}=0.70,0.60$ and 0.45 . Therefore, it is confirmed that PEG400 fulfills the self-curing function.

2. The optimal dosage of PEG 400 determined was $1 \%$ of the cement weigh, which provided the best results in compressive strength for $\mathrm{w} / \mathrm{c}=0.70,0.60$ and 0.45 studied at 7,14 and 28 days. Thus, it was the dosage chosen to study other properties of concrete.

3. In respect of compressive strength, at early ages ( 7 and 14 days), higher results and growth rates are obtained in sample $\mathrm{SC}+1.0 \% \mathrm{wc}$ in comparison with sample $\mathrm{CC}+0.0 \% \mathrm{wc}$, for $\mathrm{w} / \mathrm{c}=0.70,0.60$ and 0.45 , which could be explained due to the fact that PEG 400 promotes better hydration in early days because of its capacity for retaining humidity. In addition, at 28 days, the growth rate in compressive strength decreased compared to the increase recorded in early days, which could be attributed to the fact that remaining hydration reactions were produced in sample $\mathrm{CC}+0.0 \% \mathrm{wc}$ because of availability of water curing, what conferred a better performance in strength gain in comparison with sample $\mathrm{SC}+1.0 \% \mathrm{wc}$.

4. PEG 400 performs best for low w/c ratios, which is particularly evident in the case of $\mathrm{w} / \mathrm{c}=0.45$ with $1 \%$ of PEG 400 , in which at 28 days, an increase of $5.5 \%$ in compressive strength, a growth of $5.1 \%$ in splitting tensile strength and a rise of $2.2 \%$ in modulus of rupture are obtained with respect to the conventionally cured concrete.

5. SEM test provides a qualitative description of the characteristics of crystal formation (products of the concrete hydration), which demonstrates that similar characteristics are shared for samples $\mathrm{SC}+1.0 \% \mathrm{wc}$ and $\mathrm{CC}+0.0 \% \mathrm{wc}$. Likewise, in both cases the concentrated multidirectional links among cement particles are clearly observed at 7 days, and the finally consolidated crystals at 28 days.

6. The application of self-curing method using PEG 400 results effective and ecological since it leads to saving water, seen as a scarce natural resource, due to the fact that water will not be used to cure concrete. Moreover, the implementation of this method proposes an effective curing alternative in areas with limited access to water.

\section{ACKNOWLEDGMENT}

This research was supported by the Research Institute of the School of Civil Engineering of the National University of Engineering. The authors gratefully acknowledge the technical support provided by the FIC Materials Testing Laboratory.

\section{REFERENCES}

[1] ACI 308R-01, "Guide to curing concrete," American Concrete Institute, 2001.

[2] ASTM International, ASTM C 31, "Standard Practice for Making and Curing Concrete Test Specimens in the Field," ASTM2015.

[3] S.M. Junaid, S.M, "Self-curing concrete," Magazine of International Journal of Advance Foundation and Research in Science \& Engineering (IJAFRSE), 1(1), 1-7, 2015.

[4] R. Henkensiefken, T. Nantung \& W. Weiss, "Internal Curing - From the Laboratory to Implementation," International Bridge Conference, 2009.

[5] I. Amaro, "Estudio de la variación de la resistencia en compresión en concretos de alta resistencia debido al curado en Laboratorio y bajo condiciones de obra," Universidad Nacional de Ingeniería, Nota Técnica, 2002.

[6] B. Baradan \& H. Un, "The effect of curing temperature and relative humidity on the strength development of Portland cement mortar," Scientific Research and Essays, 6(12), 2504-2511, 2011.

[7] M. V. Jagannadha, "Strength characteristics of self-curing concrete," Magazine of International Journal of Research in Engineering and Technology, 1, (1), 51-57, 2012.

[8] S. Azhagarsamy \& S. Sundararaman, "A Study on Strength and Durability of Self Curing Concrete Using Polyethylene Glycol-400," Internacional Journal of Civil Engineering and Concrete Structures, 1 (2), 2016.

[9] Abdel-Reheem, A. Mahdy, M. Mousa \& M. Yehia, "Self-curing concrete types; water retention and durability," Alexandria Engineering Journal, 2015.

[10] B. Krishna \& R. Jaipal, "Comparative and Experimental Study on Self Curing Concrete," International Journal of Research Sciences and Advanced Engineering, 2017.

[11] G. Abishek, "Experimental Investigation of High - Strength Characteristics of Self Curing Concrete," International Journal for Modern Trends in Science and Technology, 2016.

[12] J. Daliya, "Effect of Self Curing Agents on Mechanical Properties of Concrete," International Journal of Engineering Research \& Technology (IJERT), 2016.

[13] ASTM International, ASTM C 192, "Standard Practice for Making and Curing Concrete Test Specimens in the Laboratory," ASTM 2016.

[14] ASTM International, ASTM C 39, "Standard test method for compressive strength of cylindrical concrete specimens," ASTM 2015.

[15] ASTM International, ASTM C 496, "Standard Test Method for Splitting Tensile Strength of Cylindrical Concrete Specimens," ASTM 2016.

[16] ASTM International, ASTM C 78, "Standard Test Method for Flexural Strength of Concrete (Using Simple Beam with Third-Point Loading)," 2015.

[17] ASTM C 1074. "Standard Practice for Estimating Concrete Strength by the Maturity Method," ASTM 2017.

$\mathbf{1 8}^{\text {th }}$ LACCEI International Multi-Conference for Engineering, Education, and Technology: "Engineering, Integration, and Alliances for a Sustainable Development" "Hemispheric Cooperation for Competitiveness and Prosperity on a Knowledge-Based Economy", 29-31 July 2020, Buenos Aires, Argentina. 10 